\title{
Dynamic Performance Analysis of VSC-HVDC Based Modular Multilevel Converter under Fault
}

\author{
Abdelhalim Yahiaoui $^{1 *}$, Koussaila Iffouzar ${ }^{1,2}$, Kaci Ghedamsi ${ }^{1}$, Kamal Himour ${ }^{3}$ \\ ${ }^{1}$ Laboratoire de Maitrise des Énergies Renouvelables, Faculté de Technologie, Université de Béjaia, Béjaia 06000, Algeria \\ ${ }^{2}$ Ecole supérieure des Sciences Appliquées d'Alger, Département Second Cycle, Alger 16000, Algeria \\ ${ }^{3}$ Département de Sciences et Technologies, Institut de Science, Centre Universitaire Nour Bachir, El Bayadh 32000, Algeria
}

Corresponding Author Email: yahiaouiabdelhalim@hotmail.fr

https://doi.org/10.18280/jesa.540121

Received: 11 June 2020

Accepted: 20 October 2020

\section{Keywords:}

high voltage direct current, voltage source converter, modular multilevel converter, vector oriented control, AC fault

\begin{abstract}
The use of high voltage direct current based voltage source converter (VSC-HVDC) in power transmission systems knows a great progress in recent years. Above all, with the new generation of power electronics converters such as the modular multi-level converter (MMC), with his scalable structure it can theoretically meet any voltage level requirement, which allows to increase the size of the power transferred compared to conventional converters. In this sense, this paper presents a study of a VSC-HVDC system based on a modular multi-level converter (MMC). The main objective of this work is to analyze the performance of the VSC-HVDC system based MMC without the AC filters and its control in the event of a fault, during set point changes and unbalanced grid conditions. After realization a mathematical model of the system studied and its control, simulations are done over in Simpower System/Matlab. The results obtained confirm the robustness of the system control and the system gives a good energy quality, that manifests by a good output currant and voltage curves with no need to use a voluminous AC filter.
\end{abstract}

\section{INTRODUCTION}

The need for high powers range in recent years requires more reliable methods of transporting energy in the event of a breakdown, as well as appropriate equipment and means of production. For this purpose, HVDC transport arouses more interest, mainly for their economic factor for the exploitation of production in offshore deposits, such as wind turbines [1], water pipes and for the connection of asynchronous networks.

For several years, HVDCs based on thyristor (CSC) were used [2, 3]. Supported by the developments in power electronics, semiconductors and control techniques, converters based on IGBT called Voltage Source Converters (VSC) have emerged, which enabled the development of HVDC based on this converter, where several functional commercial projects are listed worldwide $[1,4]$. This kind of converters presents many advantages compared to the CSC, such as a rapid control of active and reactive powers and provides a high power quality with a minimal environmental impact [5]. The CSC converter operating principle is based on keeping a constant the DC current and gives only one degree of freedom at each terminal, and the power reversal is achieved by reversing the polarity of the direct voltages at both terminals, which represents a solution, mostly delicate in multi terminal operation. However, in the case of VSCs converters there are two degrees of freedom at each terminal, the control of the current and the voltage that gives an independent control of active and reactive powers [6].

In addition, VSC converters operation does not require reactive power, in contrary of the CSC converters, and their reactive power can be used to regulate the $\mathrm{AC}$ voltage. Moreover, the power in the VSC is controlled by changing the direction of the current, which makes them more attractive in multi-terminal applications [7].

Furthermore, the research has also made possible the emergence of new multilevel converter topologies allowing the rise in voltage and power. One of these new topologies is the modular multilevel converter (MMC) [8], it belongs to the multi cell converter family. This converter gives a way to eliminate the need of isolated DC sources [9], but the main advantages of this converter is it's modularity, that allows increasing the voltage level easily, reduction of power supplies on the semiconductor and permits to get an output voltage with a low harmonic distortion [10] that can gives an opportunity to delete the AC filter. In addition, this converter is commonly used in power compensation as the STATCOM applications [11].

The present work is part of the perspective to study the performance and stability of a VSC-HVDC system based on a high level MMC in the event of dispensing the AC filters. Thus, simulations of the MMC-HVDC system studied were carried out in Simpower System of Matlab, the control of this system is based on vector oriented control.

This paper is presented as follows: Firstly, the mathematic models of the different systems are done. After that, we present and detail the control system. Then, simulations of the system are done under different perturbations and faults in the AC grid. Finally, the results obtained and the performances of the VSC-HVDC based MMC system are analyzed and discussed. 


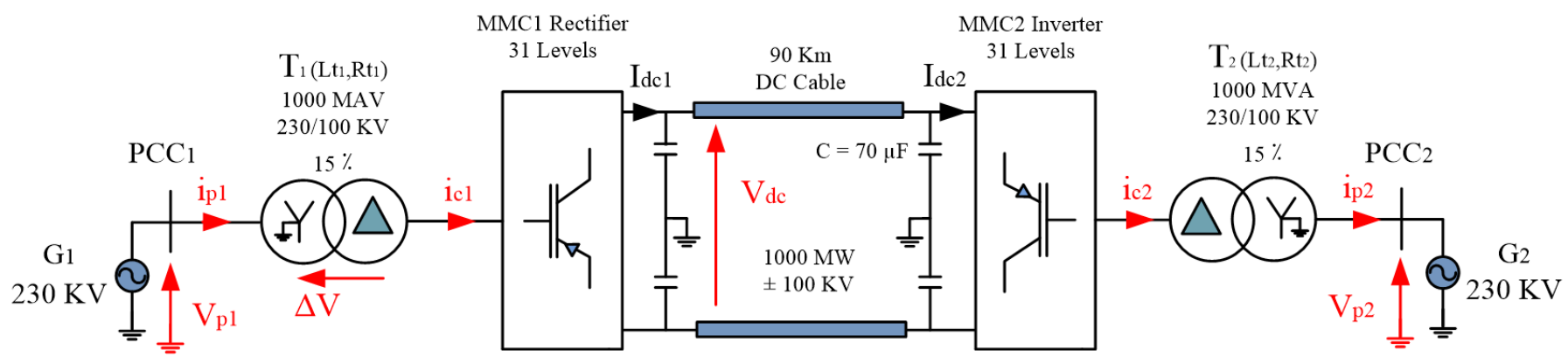

Figure 1. Typical schematic of VSC-HVDC system

\section{SYSTEM DESCRIPTION}

Figure 1 illustrates a VSC-HVDC system. It consists of two identical voltage source converters (VSC) connected in back to back or via DC lines [12]. Usually the converters are connected to the AC system via an AC filter and power transformers, in the case of a high-level voltage at the output of the converter, the AC filter can be removed. The equivalent phase reactors $X$ are used to control the active and reactive power by regulating the current flowing and to reduce the high frequency harmonic content of the $\mathrm{AC}$ line current caused by the switching of the VSC ripple. On the AC voltage and current. The transformers reduce the $\mathrm{AC}$ voltage to a value suitable for the converter. The AC side capacitors provide an energy buffer to keep the power balance during transients and reduce the voltage ripple on the DC side [13]

\section{SYSTEM MODELING}

The circuit topology of a three phase $\mathrm{N}+1$ level MMC connected to the AC grid through a power transformer is shown in Figure 2 (a). Each phase-leg comprises an upper and lower arm and each arm is a cascaded connection of $\mathrm{N}$ identical sub modules (SM) made of a half bridge, as shown in Figure 2 (b). The operation of switches within SM is complimentary, so, the SM output voltage is either equal to its capacitor voltage $\left(\mathrm{V}_{\mathrm{SM}}\right)$ or zero, depending on the switching states of the switch pairs $S_{1}$ and $S_{2}$ as reported in Table 1. Each switch is an IGBT with an anti-parallel diode.

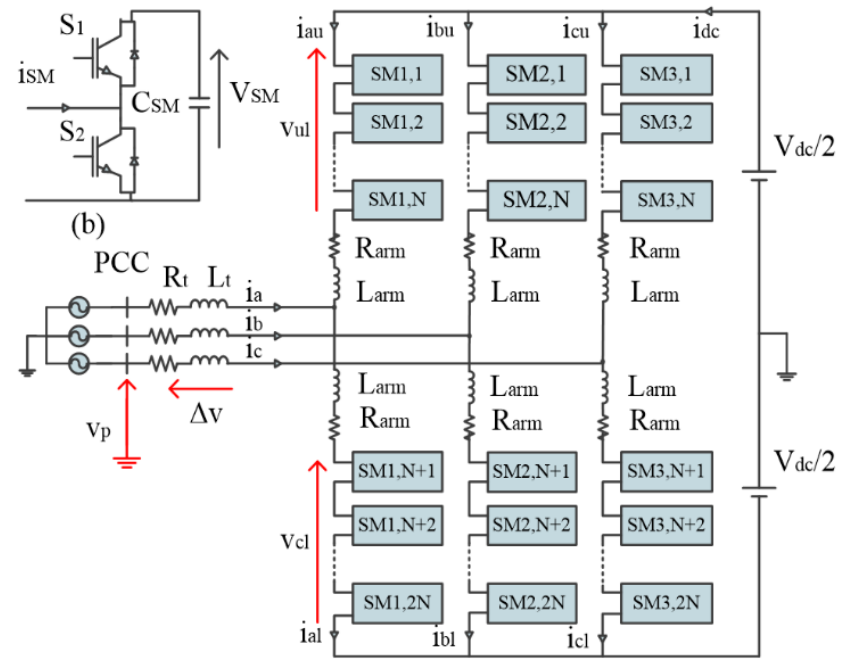

(a)

Figure 2. (a) Schematic representation of an N Level MMC (b) Sub-Module
Table 1. SM states and its output voltage

\begin{tabular}{ccccccc}
\hline S1 & S2 & D1 & D2 & Current & $\begin{array}{c}\text { Capacitor } \\
\text { state }\end{array}$ & $\begin{array}{c}\text { Output } \\
\text { voltage }\end{array}$ \\
\hline OFF & ON & OFF & OFF & $i_{\text {arm }}>0$ & Uncharged & 0 \\
OFF & OFF & OFF & ON & $i_{\text {arm }}<0$ & Uncharged & 0 \\
ON & OFF & ON & OFF & $i_{\text {arm }}>0$ & Charge & Vc \\
ON & OFF & OFF & OFF & $i_{\text {arm }}<0$ & Discharging & Vc \\
\hline
\end{tabular}

The $L_{\text {arm }}$ and $R_{\text {arm }}$ are inserted in the circuit to control the circulating current and limit the fault currents.

An insertion index $n(t)$ is use to control each arm, where $n$ $(t)=0$ means that all sub-modules are deactivated, contrariwise, $\mathrm{n}(\mathrm{t})=1$ means that all the sub-modules in the arm are activated.

Assuming that the capacitors voltage is kept to the reference voltage $V_{c}^{*}=V_{d c} / N$ using a voltage-balancing algorithm [13] Eq. (1) and Eq. (2) give the instantaneous arm voltages.

$$
\begin{aligned}
& v_{c u}=n_{u}(t) \cdot \sum_{l}^{N} u_{c u} \\
& v_{c l}=n_{l}(t) \cdot \sum_{l}^{N} u_{c l}
\end{aligned}
$$

$n_{u}(t)$ and $n_{l}(t)$ represent the insertion indices for upper and lower arm, respectively.

$\sum_{1}^{N} u_{c u}$ and $\sum_{1}^{N} u_{c l}$ are, respectively, the total of SMs capacitor voltage in the upper and lower.

The mathematical relation between the arm, output and circulating currents is given by Eq. (3) and Eq. (4) [14]:

$$
\begin{gathered}
i_{u, j}=\frac{i_{d c}}{3}+i_{c i r c, j}+\frac{i_{j}}{2} \\
i_{l, j}=\frac{i_{d c}}{3}+i_{c i r c, j}-\frac{i_{j}}{2}
\end{gathered}
$$

With, $i_{\text {circ }}$ is the circulating current within phase- $j, i_{u}$, and $i_{1}$, are the upper and lower current of phase- $j, i_{j}$ represents the AC side current within phase- $j$ and $i_{d c}$ is the DC side current.

The current within the phase $\mathrm{j}$ is obtained as:

$$
i_{j}=i_{l, j}-i_{u, j}
$$

Eq. (5) and Eq. (6) give the dynamic behavior of the upper and lower arm of the phase-leg-j. 


$$
\begin{aligned}
& \frac{V_{d c}}{2}-v_{u, j}=L_{a r m} \frac{d i_{u, j}}{d t}+R_{a r m} i_{u, j}+v_{j} \\
& \frac{V_{d c}}{2}-v_{l, j}=L_{a r m} \frac{d i_{l, j}}{d t}+R_{a r m} i_{l, j}-v_{j}
\end{aligned}
$$

The subtraction of Eq. (7) from Eq. (6) gives:

$$
v_{j}-\frac{v_{l, j}-v_{u, j}}{2}=\frac{L_{a r m}}{2} d\left(\frac{i_{l, j}-i_{u, j}}{d t}\right)+\frac{R_{a r m}}{2}\left(i_{l, j}-i_{u, j}\right)
$$

The addition of Eq. (6) and Eq. (7) gives :

$$
V_{d c}-\left(v_{u j}-v_{l, j}\right)=L_{a r m} \frac{d}{d t}\left(i_{u, j}+i_{l, j}\right)+R_{a r m}\left(i_{u, j}+i_{l, j}\right)
$$

We operate a variable changing [15]:

$$
\begin{gathered}
v_{c d c, j}=v_{u, j}+v_{l, j} \\
v_{c, j}=\frac{v_{l, j}-v_{u, j}}{2} \\
i_{d i f f, j}=\frac{i_{u, j}+i_{l, j}}{2}
\end{gathered}
$$

Then, we insert Eq.10, Eq. 11 and Eq. 12 in Eq. 8 and Eq.9 the mathematical equation of the phase voltage in Eq. 13:

$$
v_{j}=v_{c, j}+\frac{L_{a r m}}{2} \frac{d i_{j}}{d t}+\frac{R_{a r m}}{2} i_{j}
$$

\section{CONTROL SYSTEM BASED ON VECTOR ORIENTED CONTROL (VOC)}

The main objective of the VSC-HVDC control system is to maintain the stability of the power transfer. Therefore, this power transfer must do with lowest oscillations when the references change. As well, another objective is the regulation of the DC voltage to a reference value, since an extended operation outside the admissible voltages can affect equipment; mainly the power switches [3].

The control system of a VSC-HVDC system, as shown in Figure 3 is based on two controller loops, the inner fast loop controller and the outer lower loop controller.

The inner loop controller controls the current in the $\mathrm{AC}$ side of the VSC [16]. The outer loop feeds the current references to the inner loop in order to maintain an adequate voltage reference for the VSC; it includes the DC voltage regulator, the $\mathrm{AC}$ voltage regulator and the active and reactive power regulators [17]. However, all these regulators cannot be used in the same time, the choice of the controller depends on the application mode of the VSC-HVDC system. Indeed, the direct current reference is used to control the active power or the DC voltage and the quadratic current reference is used to control the reactive power or the $\mathrm{AC}$ voltage. In our case, we use a reactive power controller with the DC voltage controller and the active power controller.

\subsection{Inner current loop}

From Figure 2, the equations Eq. (14) and Eq. (15) can be deduced for each phase, $\mathrm{j}=\mathrm{a}, \mathrm{b}, \mathrm{c}$.

$$
\frac{V_{d c}}{2}=v_{u, j}+L_{a r m} \frac{d i_{u, j}}{d t}+R_{a r m} i_{u, j}-L_{t} \frac{d i_{j}}{d t}-R_{t} i_{j}+v_{p, j}
$$

$$
\frac{V_{d c}}{2}=v_{l, j}+L_{a r m} \frac{d i_{l, j}}{d t}+R_{a r m} i_{l, j}+L_{t} \frac{d i_{j}}{d t}+R_{t} i_{j}-v_{p, j}
$$
(11):

$$
v_{p, j}-v_{c, j}=\left(\frac{L_{a r m}}{2}+L_{t}\right) \frac{d i_{j}}{d t}+\left(\frac{R_{a r m}}{2}+R_{t}\right) i_{j}
$$

Then, we consider a balanced three-phase system, the Eq. (16) is transformed into a rotating $\mathrm{dq}$ frame:

$$
\left\{\begin{array}{l}
V_{p d}-V_{c d}=L \frac{d I_{d}}{d t}+R I_{d}-\omega L I_{q} \\
V_{p q}-V_{c q}=L \frac{d I_{q}}{d t}+R I_{q}+\omega L I_{d}
\end{array}\right.
$$

where, $\omega$ is the angular frequency, $L=\left(\frac{L_{\text {arm }}}{2}+L_{t}\right)$ is the total equivalent inductance and $R=\left(\frac{R_{\text {arm }}}{2}+R_{t}\right)$ is the equivalent resistance of the system. In high voltage, the resistance $\mathrm{R}$ is usually neglected [18].

Unfortunately, due to the coupling between the equations of Eq. (17), it is not possible to get a direct controller. Thus, a fast feedback dq decoupled current controller are employed, based on insertion of PI controllers with considering the coupling terms [19].

$$
\left\{\begin{array}{l}
V_{c d}^{r e f}=-\left(k_{p i}+\frac{k_{i i}}{s}\right)\left(I_{d}^{r e f}-I_{d}\right)+\omega L I_{q}+V_{p d} \\
V_{c q}^{r e f}=-\left(k_{p i}+\frac{k_{i i}}{s}\right)\left(I_{q}^{r e f}-I_{q}\right)-\omega L I_{d}+V_{p q}
\end{array}\right.
$$

\subsection{Outer loop control}

The outer control loop feeds the current references to the inner loop. Depending on the operation mode, the $\mathrm{d}$ component of the reference current is used to control the DC voltage or the active power. And the q component is used to control the $\mathrm{AC}$ voltage or the reactive power. This control is based on a PI controller who give a fast response compared to the direct control [19].

The active power $\mathrm{P}$ and the reactive power $\mathrm{Q}$ transmitted in the $\mathrm{AC}$ system and the $\mathrm{DC}$ power $\mathrm{P}_{\mathrm{dc}}$ are given in the $\mathrm{dq}$ frame as [17]:

$$
\begin{gathered}
P=V_{p d} I_{p d}+V_{p q} I_{p q} \\
Q=-V_{p d} I_{p q}+V_{p q} I_{p q} \\
P_{d c}=V_{d c} I_{d c}
\end{gathered}
$$


(a) Active power controller

If the AC voltage of the converter is aligned with the $\mathrm{d}$ axis and kept at $1 \mathrm{pu}\left(\mathrm{V}_{\mathrm{pd}}=1 \mathrm{pu}\right.$ and $\left.\mathrm{V}_{\mathrm{pq}}=0\right)$, the expressions of $\mathrm{P}$ and Q become:

$$
\begin{gathered}
P=V_{p d} I_{p d} \\
Q=-V_{p d} I_{p q}
\end{gathered}
$$

The active power controller is obtained from Eq. (22) with insertion of a PI regulator.

$$
I_{p d}^{r e f}=\frac{1}{V_{p d}}\left(k_{p p}-\frac{k_{i p}}{s}\right)\left(P^{r e f}-P\right)
$$

(b) DC voltage controller

The aim of the DC voltage controller is to maintain the balance in power transfer. Indeed, if the DC voltage changes it affects the power flow between the two AC stations. The relation between the DC voltage, the AC current and the DC current is given in the dq frame by Eq. (25) [15].

$$
6 C_{a r m} \frac{d V_{d c}}{d t}=i_{d}-I_{d c}
$$

The DC voltage regulator based on PI controller is given in the equation Eq. (26):

$$
I_{p d}^{r e f}=\left(k_{p d c}-\frac{k_{i d c}}{s}\right)\left(V_{d c}^{r e f}-V_{d c}\right)
$$

(c) Reactive power controller

The reactive power controller is obtained from Eq. (22) with insertion of a PI regulator.

$$
I_{p q}^{r e f}=\frac{1}{V_{p d}}\left(k_{p q}-\frac{k_{i q}}{s}\right)\left(Q^{r e f}-Q\right)
$$

(d) AC Voltage controller [20]:

Eq. (28) estimates the voltage drop over the total reactance

$$
\Delta v_{p}=v_{c}-v_{p} \simeq \frac{R P+\omega L Q}{v_{p}}
$$

In high voltage applications $\omega L \gg R$, then $R$ is neglected. The $v_{p}$ vector is aligned with $d$ axis, Eq. (23) in Eq. (28):

$$
\Delta v_{p} \simeq \omega L i_{q}
$$

The AC voltage regulator based on PI controller is given in the equation Eq. (30):

$$
I_{q}^{r e f}=\left(k_{p a c}+\frac{k_{i a c}}{s}\right)\left(V_{a c}^{r e f}-V_{a c}\right)
$$

\section{SIMULATION STUDY}

In the way to analyse the behaviour of the VSC-HVDC system and testing the response of the designed control, the system explained in Figure 3 and his control system are simulated in MATLAB/SimPowerSystems under different conditions and transients. A detailed model of thirty-one level MMC is used and his parameters are reported in Table 2.

Table 2. VSC-HVDC base MMC system parameters

\begin{tabular}{cccc}
\hline Parameter & Symbol & Value & Value in pu \\
\hline Rated (base) AC voltage & $\mathrm{V}_{\mathrm{ac}}$ & $100 \mathrm{e} 3$ & 1.0 \\
DC Voltage & $\mathrm{V}_{\mathrm{dc}}$ & $200 \mathrm{e} 3$ & 1.0 \\
Rated (base) power & $\mathrm{P}$ & $1000 \mathrm{e} 6$ & 1.0 \\
Transformer inductance & $\mathrm{L}_{\mathrm{t}}$ & $0.075 \mathrm{H}$ & \\
Transformer resistance & $\mathrm{R}_{\mathrm{t}}$ & $0.0025 \Omega$ & \\
DC capacitor & $\mathrm{C}_{\mathrm{dc}}$ & $70 \mu \mathrm{F}$ & \\
System frequency & $\mathrm{f}$ & $50 \mathrm{~Hz}$ & \\
Switching frequency & $\mathrm{f}_{\mathrm{c}}$ & $150 \mathrm{~Hz}$ & \\
Number of SM & $\mathrm{N}$ & 30 & \\
Number of level & & 31 & \\
SM capacitor & $\mathrm{CSM}_{\mathrm{S}}$ & $0.001 \mathrm{~F}$ & \\
Arm inductance & $\mathrm{L}_{\mathrm{arm}}$ & $1 \mathrm{e}-5 \mathrm{H}$ & \\
Arm inductance & $\mathrm{R}_{\mathrm{arm}}$ & $1 \mathrm{e}-5 \Omega$ & \\
\hline
\end{tabular}

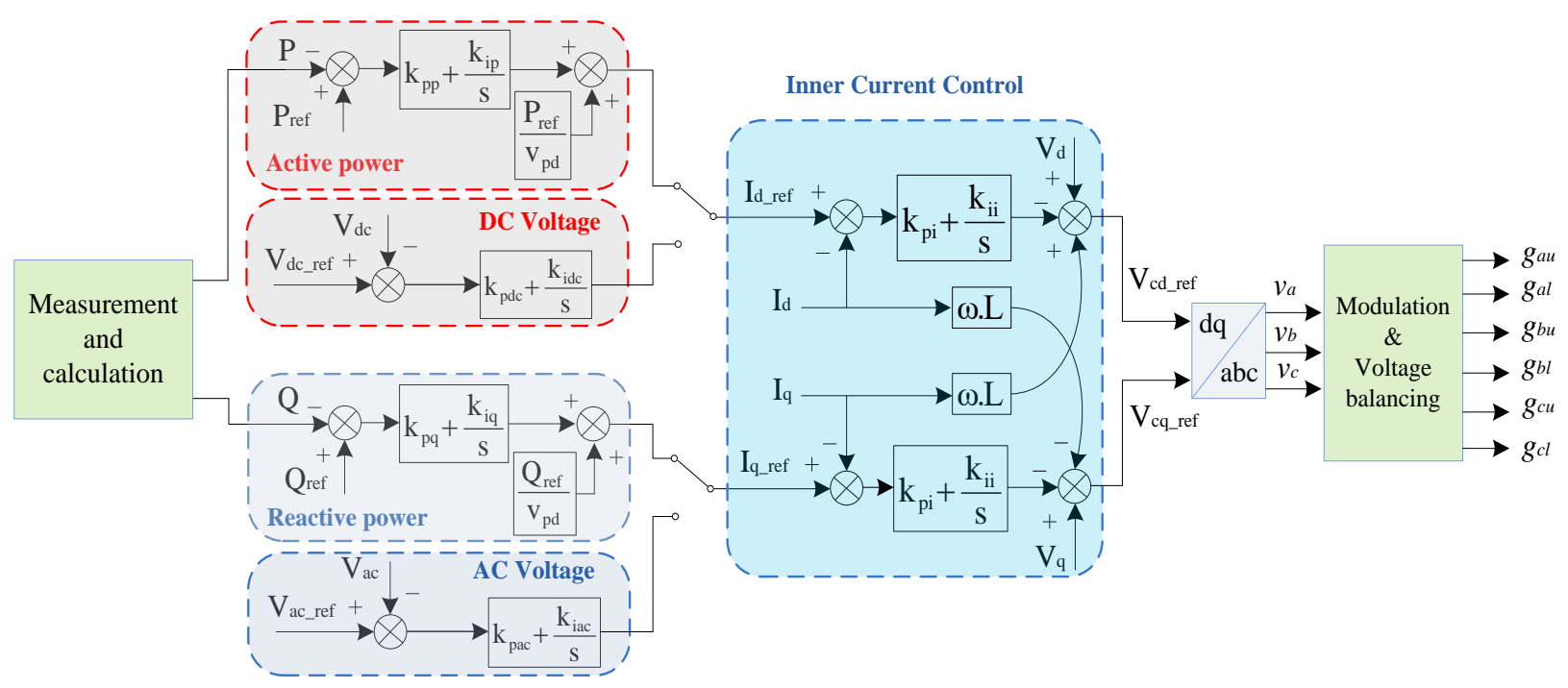

Figure 3. Vector control of a VSC-HVDC based MMC 


\subsection{AC voltage step in grid 1}

The reference of $\mathrm{AC}$ voltage in grid 1 changes from $1 \mathrm{pu}$ to $0.8 \mathrm{pu}$ at $0.8 \mathrm{~s}$ for four (04) periods. As shown in Figure 4, the voltage and current in grid 2 stay not affected by the AC voltage step. In the other hand, the voltage in the grid 1 increase smoothly, but his current presents a transient to compensate the AC voltage step who caused the phase angle change.
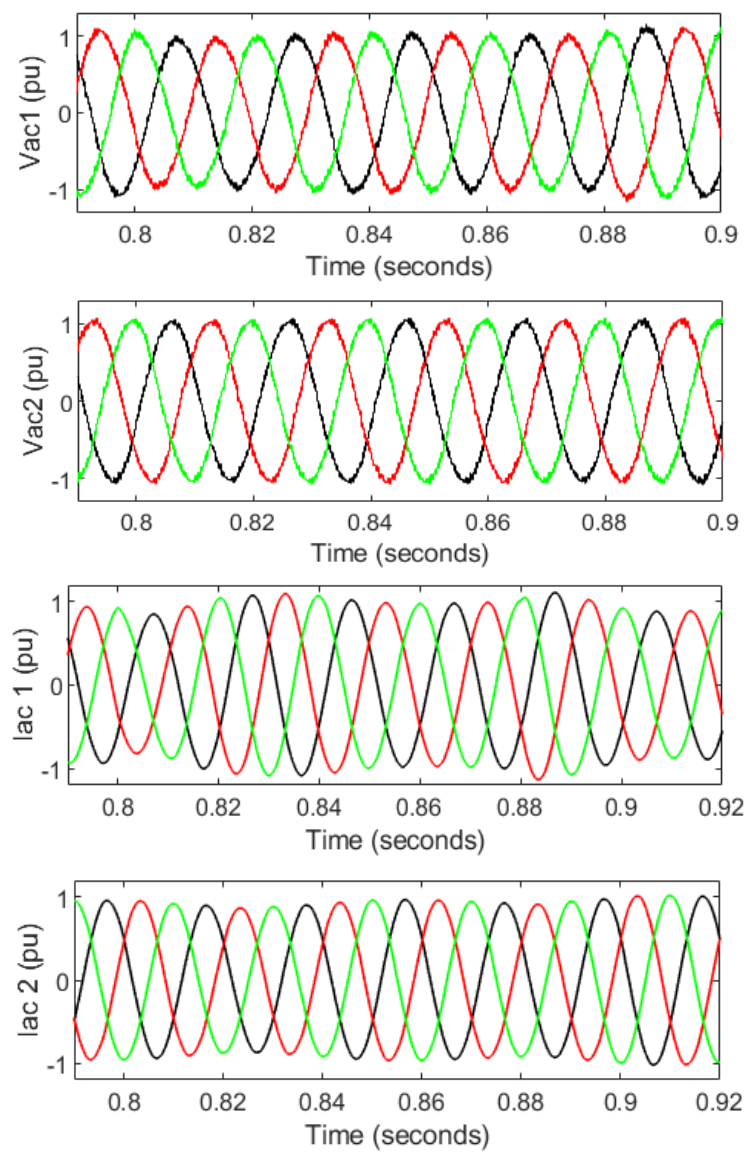

Figure 4. $\mathrm{AC}$ voltage and current in $\mathrm{PCC} 1$ and 2
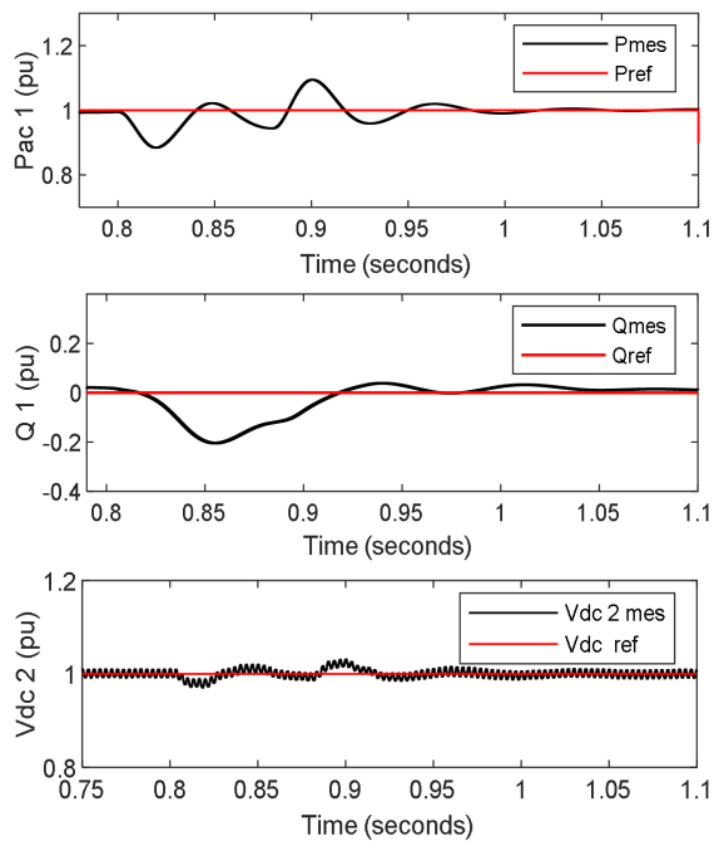

Figure 5. Active and reactive power and DC voltage
Figure 8 shows the response of DC voltage during the AC voltage step, it appears that, except for a small transient, the $\mathrm{DC}$ voltage is kept to its reference value by the $\mathrm{DC}$ controller. Also, in Figure 5 the operating point of the converter 1 is caused by the $\mathrm{AC}$ voltage step, that manifests by an absorption of a reactive power to compensate the voltage step and a fluctuation appear in active power who are regulated as soon.

\subsection{Active power step in grid 1}
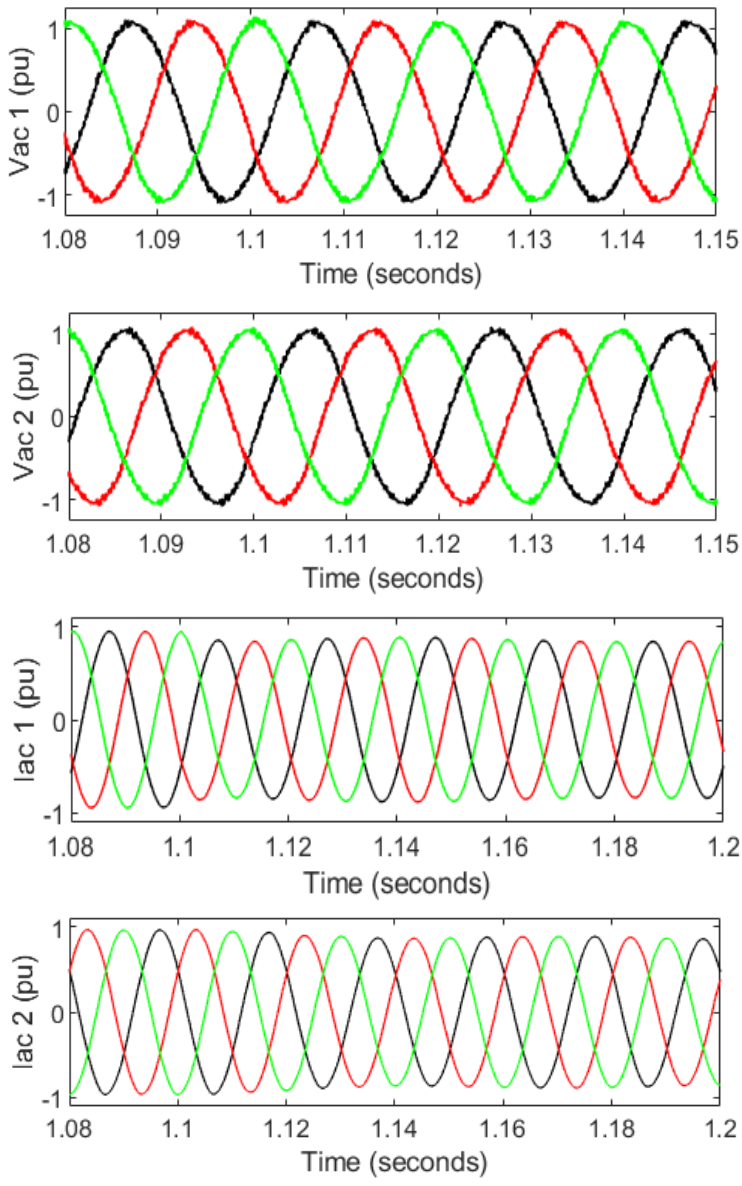

Figure 6. AC voltage and current in PCC 1 and 2
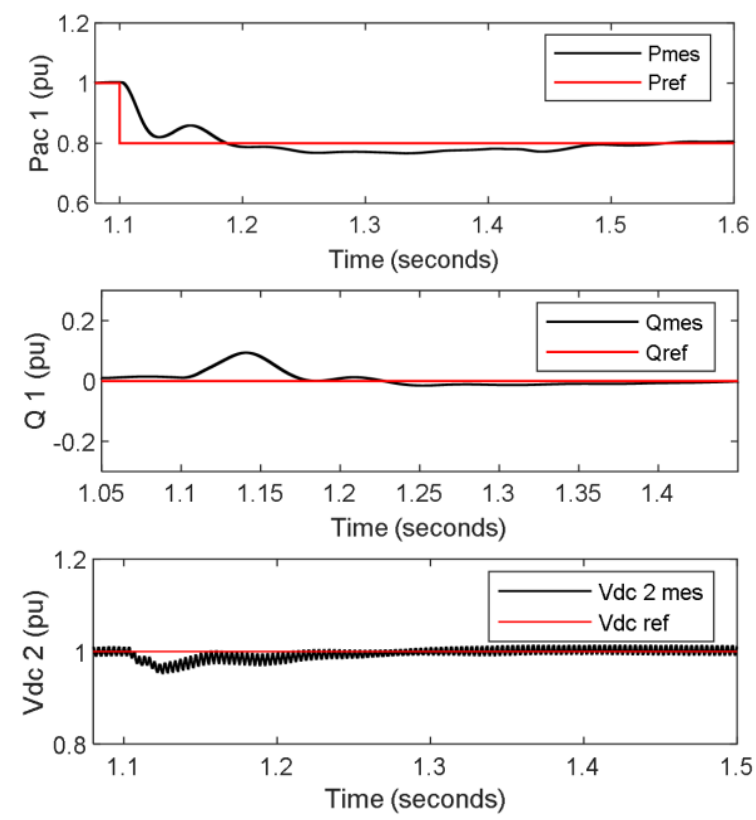

Figure 7. Active and reactive power and DC voltage 
The reference of the active power in grid 1 is instantly changed at 1.1 from 1 pu to 0.8 pu $\mathbf{s}$. From the responses of the $\mathrm{AC}$ voltages and currents for the two sides shown in Figures 6, we notice that only the AC voltage in grid 1 is affected with a small transient. However, the AC currents in both sides suffered a transient then they are stabilized by adapting the new power reference.

The Figure 7 shows the responses of active and reactive power transmitted and the DC voltage, we observe that the active power is stabilized to her new reference value after 0.15 $\mathrm{s}$, the reactive power suffered a maximal perturbation of 0.06 pu and stabilized after $0.3 \mathrm{~s}$. Moreover, we observe a voltage drop in a DC voltage and is stabilized after $0.2 \mathrm{~s}$.

\subsection{Reactive power step in grid 1}

The reactive power reference is changed from 0 pu to -0.1 pu at $1.4 \mathrm{~s}$, in the Figure 8 , we notice that the AC voltages in both sides are not affected with a low diminution in th $\mathrm{AC}$ currents.

In Figure 9, we observe a fast response of the reactive power controller, and the perturbations in active and reactive power and DC voltage are stabilized as soon.
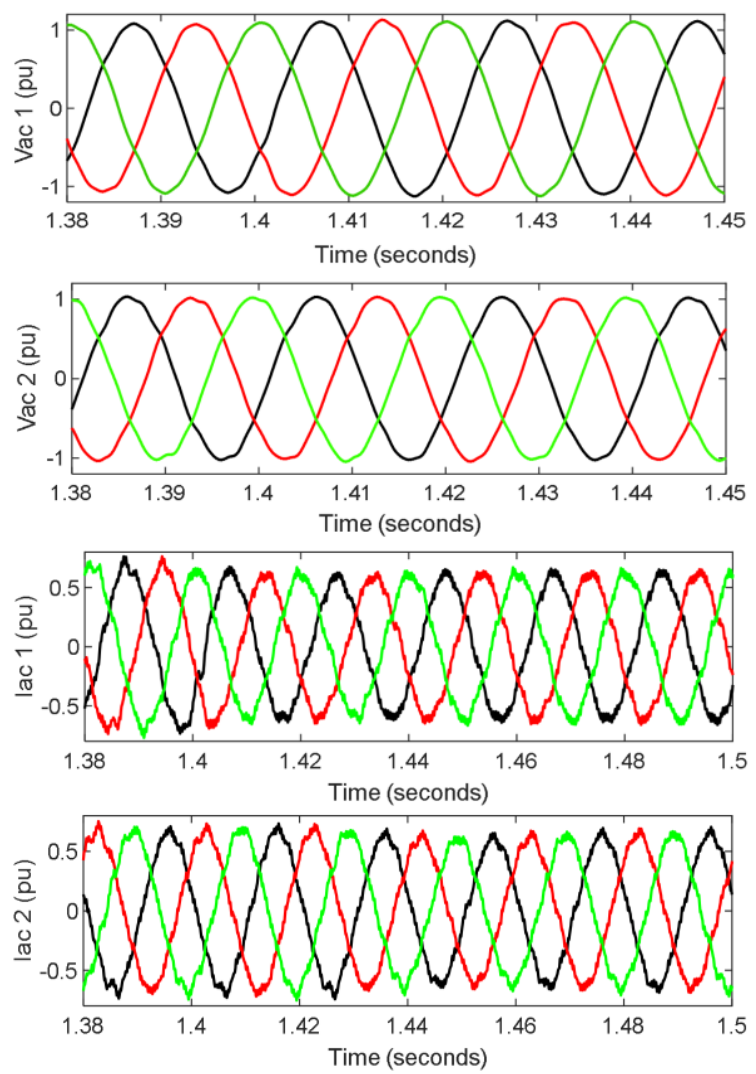

Figure 8. AC voltage and current in PCC 1 and 2

\subsection{Performances during a three-phase fault}

A three-phase-ground short-circuit of five periods is applied on the grid 2 at $t=2 \mathrm{~s}$, the purpose of this simulation is to analyze the performance of the VSC-HVDC system. Figure 10. shows that the AC voltage on side 1 increases slightly and returns to the initial value after the fault. On the other hand, we notice a sudden drop of the AC voltage on the side 2 to reach $0.2 \mathrm{pu}$, once the fault is removed and after a slight transient it stabilizes to its initial value. On the same figure, the currents on the grid 1 fall sharply to $0.17 \mathrm{pu}$. The AC current on grid 2 increases to exceed $1.4 \mathrm{pu}$, after a slight transient it stabilizes to its initial value once the default is cancelled.

In Figure 11, we observe the active power on both grids, they dropped to $0.1 \mathrm{pu}$ on side 1 and $0 \mathrm{pu}$ on side 2 . The reactive power underwent a slight disturbance and stabilized after the fault. The DC voltage increases during the fault to 1.2 $\mathrm{pu}$ and returns to its original value once the default is cancelled.
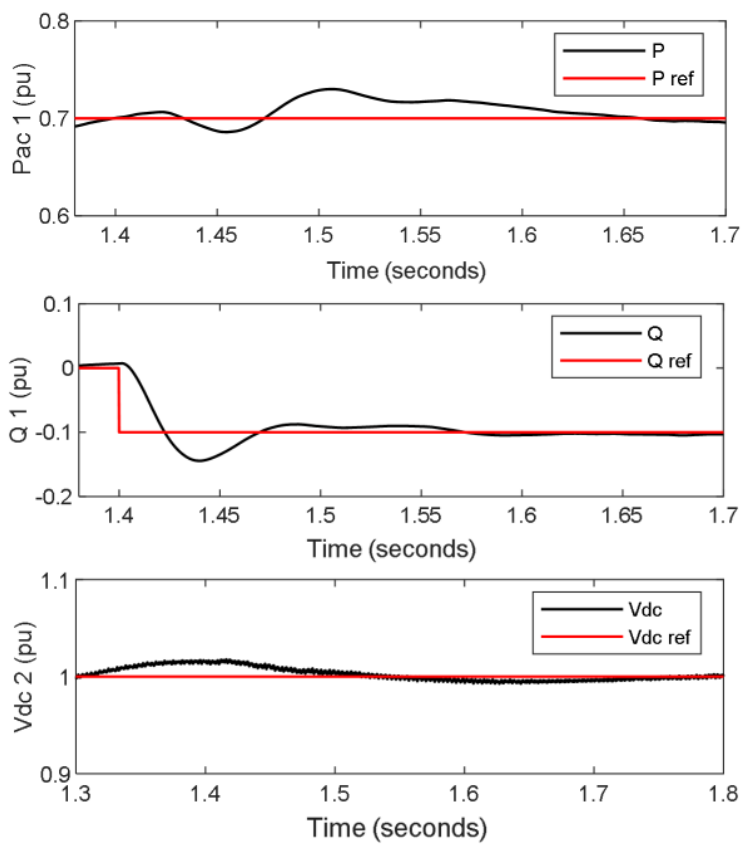

Figure 9. Active and reactive power and DC voltage
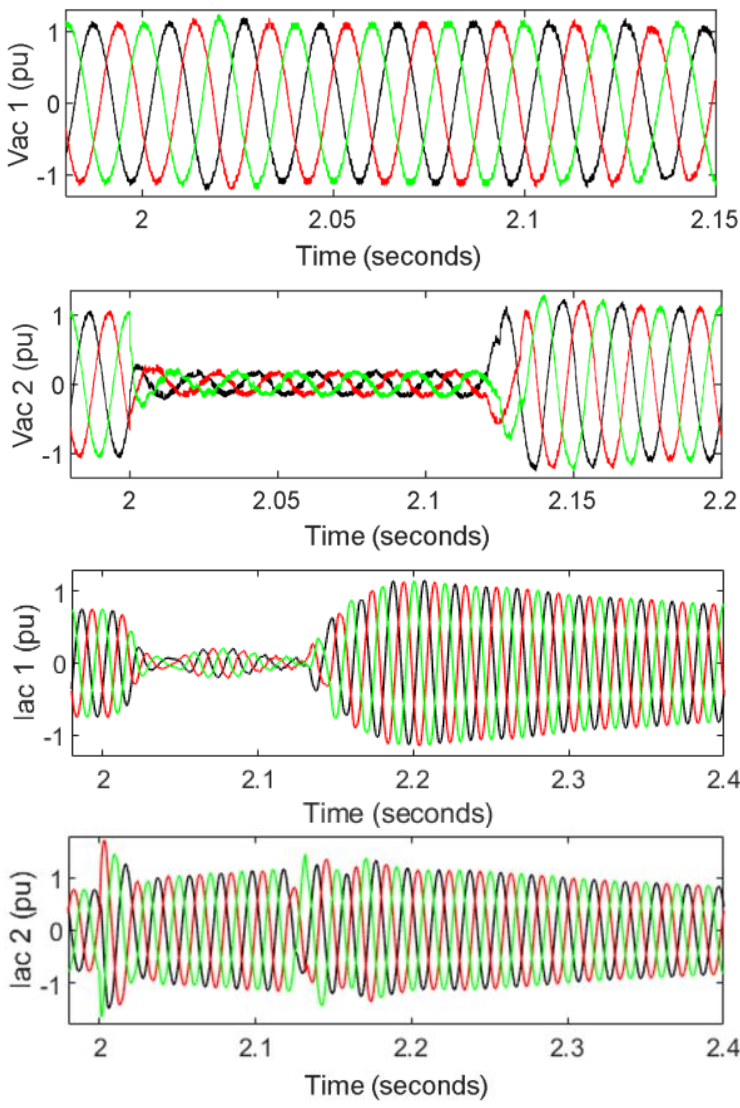

Figure 10. AC voltage and current side 1 and 2 

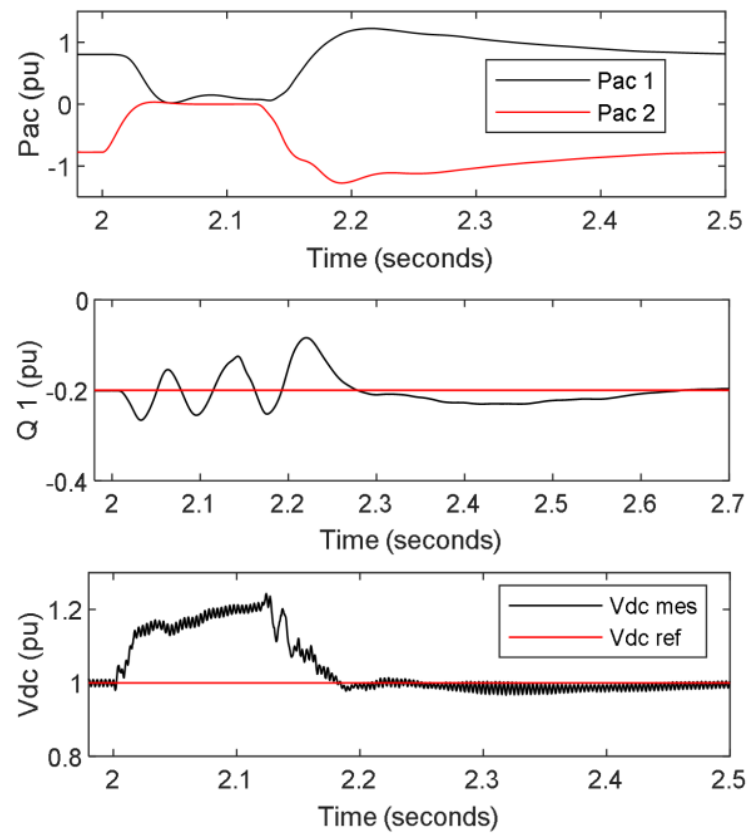

Figure 11. Active and reactive power and DC voltage

\section{CONCLUSIONS}

In this paper, the VSC-HVDC system based on MMC on 31 levels and the vector control strategy of active power, reactive power and DC bus voltage, were presented, described and simulated in Simpower System / Matlab under different conditions (steps on input powers, AC side voltage...) and disturbance (three-phase/ ground short-circuit fault). The results show that the system control has good stability and robustness performance (minimizing the impact of disturbances on currents, voltages and transmitted powers) during faults and in changing of setpoints. During a threephase short-circuit fault, an increase in alternating currents on the failing side and a decrease in alternating current on the healthy side are observed, without a low affecting on the DC bus voltage. When the fault is suppressed, the system recovers his normal operation after a small transient.

As well, the system maintains a good energy quality even with the elimination of the cumbersome AC filters, due to the high number of voltage levels at the output of the converters. In addition, the suppression of this filters shows that the voltage curves are a little jugged. However, the current curves appear smooth, this is due to the use of a converters with a high level and the total inductance of the AC system.

\section{REFERENCES}

[1] Liu, Y., Li, R. (2015). A novel control method for a VSCHVDC system in a grid-connected wind farm. Turkish Journal of Electrical Engineering \& Computer Sciences, 23(6): 1558-1570. http://dx.doi.org/10.3906/elk-1402120

[2] Eremia, M., Liu, C.C., Edris, A.A. (2016). Advanced Solutions in Power Systems: HVDC, FACTS, and Artificial Intelligence. John Wiley \& Sons. http://dx.doi.org/10.1002/9781119175391

[3] Bidadfar, A., Abedi, M., Karrari, M., Gharehpetian, G.B., Tavana, S.N. (2014). Passive AC network supplying the integration of CCC-HVDC and VSC-HVDC systems. Turkish Journal of Electrical Engineering \& Computer Sciences, 22(2): 353-362. http://dx.doi.org/10.3906/elk1207-46

[4] Teeuwsen, S.P. (2011). Modeling the trans bay cable project as voltage-sourced converter with modular multilevel converter design. In 2011 IEEE Power and Energy Society General Meeting, pp. 1-8. http://dx.doi.org/10.1109/PES.2011.6038903

[5] Guan, M., Xu, Z., Chen, H. (2011). Control and modulation strategies for modular multilevel converter based HVDC system. In IECON 2011-37th Annual Conference of the IEEE Industrial Electronics Society, pp. 849-854. http://dx.doi.org/10.1109/IECON.2011.6119421

[6] Saeedifard, M., Iravani, R. (2010). Dynamic performance of a modular multilevel back-to-back HVDC system. IEEE Transactions on Power Delivery, 25(4): 2903-2912. http://dx.doi.org/10.1109/TPWRD.2010.2050787

[7] Akbar, S.M., Hasan, A. (2018). Review of high voltage DC/DC modular multilevel converters. In 2018 15th International Conference on Smart Cities: Improving Quality of Life Using ICT \& IoT (HONET-ICT), pp. 4650. http://dx.doi.org/10.1109/HONET.2018.8551473

[8] Lesnicar, A., Marquardt, R. (2003). An innovative modular multilevel converter topology suitable for a wide power range. In 2003 IEEE Bologna Power Tech Conference $\quad$ Proceedings, $3: \quad 6$ http://dx.doi.org/10.1109/PTC.2003.1304403

[9] Kunamneni, R., Ramavathu, S.N. (2019). A grid connected modular multilevel converter for photovoltaic energy conversion. Mathematical Modelling of Engineering Problems, 6(4): 535-540. https://doi.org/10.18280/mmep.060408

[10] da Silva Dias, A., Alves, J.A., Torri, P.J. (2016). Transformerless topologies for medium voltage converters. Petroleum and Chemical Industry Conference Europe, Berlin, Germany, pp. 14-16 https://doi.org/10.1109/PCICEurope.2016.7604651

[11] Nguyen, T.H., Al Hosani, K., El Moursi, M.S., Blaabjerg, F. (2018). An overview of modular multilevel converters in HVDC transmission systems with STATCOM operation during pole-to-pole DC short circuits. IEEE Transactions on Power Electronics, 34(5): 4137-4160. http://dx.doi:10.1109/TPEL.2018.2862247

[12] Lv, C., Tai, N. (2017). Control for offshore wind power integration based on modular multilevel converter. The Journal of Engineering, 2017(13): 1885-1889. http://dx.doi.org/10.1049/joe.2017.0658

[13] Yang, Y.C., Ma, S.C., Li, Y.B. (2017). Analysis and control strategy of unbalanced power in MMC-HVDC grid. The Journal of Engineering, 2017(13): 2211-2214. http://dx.doi.org/10.1049/joe.2017.0723

[14] Ängquist, L., Antonopoulos, A., Siemaszko, D., Ilves, K., Vasiladiotis, M., Nee, H.P. (2010). Inner control of modular multilevel converters-an approach using openloop estimation of stored energy. In The 2010 International Power Electronics Conference-ECCE ASIA, pp. $1579-1585$. http://dx.doi.org/10.1109/IPEC.2010.5544607

[15] Siemaszko, D. (2014). Fast sorting method for balancing capacitor voltages in modular multilevel converters. IEEE Transactions on Power Electronics, 30(1): 463-470. 
http://dx.doi.org/10.1109/TPEL.2014.2312101

[16] Saad, H., Dennetière, S., Mahseredjian, J., Delarue, P., Guillaud, X., Peralta, J., Nguefeu, S. (2013). Modular multilevel converter models for electromagnetic transients. IEEE Transactions on Power Delivery, 29(3): 1481-1489.

http://dx.doi.org/10.1109/TPWRD.2013.2285633

[17] Geetha, R.S., Deekshit, R., Lal, G. (2012). Performance analysis of a voltage source converter HVDC system connected to an independent power generating station. In 2012 IEEE International Conference on Power Electronics, Drives and Energy Systems (PEDES), pp. 17. http://dx.doi.org/10.1109/PEDES.2012.6484497

[18] Parkhideh, B., Bhattacharya, S. (2012). Vectorcontrolled voltage-source-converter-based transmission under grid disturbances. IEEE Transactions on Power Electronics, 28(2):

661-672. http://dx.doi.org/10.1109/TPEL.2012.2204071

[19] Beddard, A., Barnes, M., Preece, R. (2014). Comparison of detailed modeling techniques for MMC employed on VSC-HVDC schemes. IEEE Transactions on Power Delivery, 30(2): 579-589. http://dx.doi.org/10.1109/TPWRD.2014.2325065

[20] Du, C., Sannino, A., Bollen, M.H. (2005). Analysis of the control algorithms of voltage-source converter HVDC. In 2005 IEEE Russia Power Tech, pp. 1-7. http://dx.doi.org/10.1109/PTC.2005.4524566

\section{NOMENCLATURE}

$\begin{array}{ll}\text { AC } & \text { Alternative Current } \\ C_{d c} & \text { Dc Capacitor } \\ \text { CSC } & \text { Current Source Converter } \\ \text { DC } & \text { Direct Current } \\ \mathrm{f} & \text { System Frequency }\end{array}$

Ki

$\mathrm{kp}$

Larm

$\mathrm{Lt}$

MMC

$\mathrm{N}$

PCC

$\mathrm{R}_{\text {arm }}$

Rt

SM

$\mathrm{T}$

$\mathrm{V}$

VOC

VSC

$\mathrm{Xt}$

Switching Frequency

Grid

High Voltage Direct Current

Current

Integral

Proportional

Arm Inductance

Transformer Inductance

\section{Greek symbols}

$\omega$

System angular frequency

\section{Subscripts}

$\begin{array}{ll}\text { ac } & \text { Alternative current index } \\ \text { arm } & \text { Converter Arm } \\ \mathrm{d} & \text { Direct Axis } \\ \mathrm{dc} & \text { Direct current index } \\ \mathrm{j} & \text { Phase index } \\ \mathrm{l} & \text { Lower } \\ \mathrm{p} & \text { PCC index } \\ \mathrm{q} & \text { Quadratic axis } \\ \mathrm{t} & \text { Transformer } \\ \mathrm{u} & \text { Upper }\end{array}$

